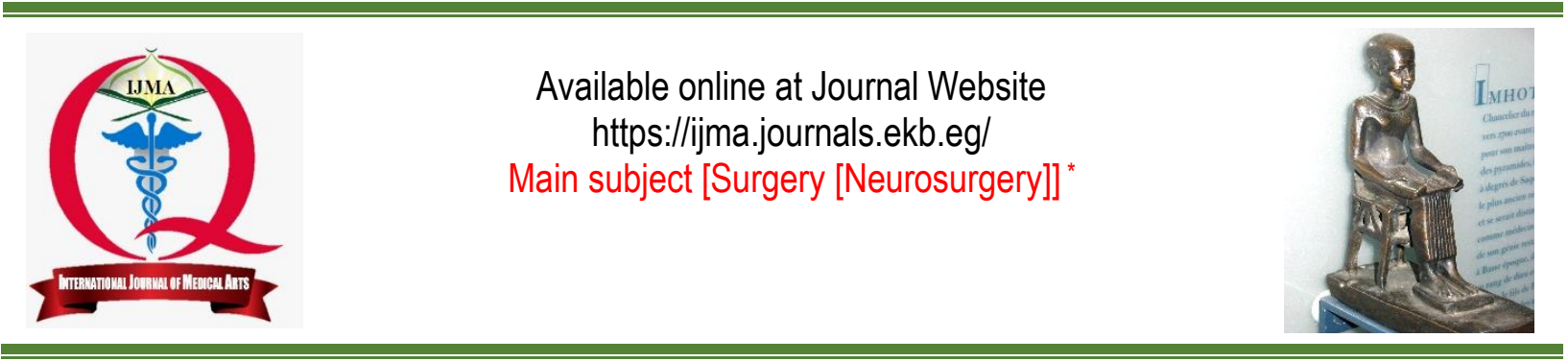

Original article

\title{
Comparative Study between Titanium Mesh and Autogenous lliac Bone Graft through Anterior Approach for Treatment of Lumbar Spondylodiscitis
}

\author{
Mohamed Selim Oda Selima; Shehab Mohamed Mohamed El khadrawy b; Mohamed Mohamed Yousef \\ Hassan $^{\mathrm{a}}$
}

Department of Neurosurgery, Damietta Faculty of Medicine, Al-Azhar University, Egypt[a] . Department of Neurosurgery, Faculty of Medicine, Al-Azhar University, Egypt ${ }^{[b]}$.

Corresponding author: Mohamed Selim Oda Selim

Email: msoda@domazhermedicine.edu.eg

Received at: December 15, 2019; Revised at: April 16, 2020; Accepted at: April 16, 2020; Available online at: April 17, 2020

DOI: 10.21608/ijma.2020.21037.1056

\section{ABSTRACT}

Background: Spondylodiscitis is an inflammation of the vertebral disk space often related to infection. Different treatment modalities were present. However, no full consensus is found about the ideal treatment.

Aim of the work: To compare between titanium mesh and autogenous iliac bone graft through anterior approach for treatment of lumbar spondylodiscitis.

Patients and Methods: A total of 30 patients with spondylodiscitis were included in the study. They were assigned for surgical intervention. They were allocated into titanium mesh or autogenous iliac bone graft through anterior approach. All underwent full history taking and clinical examination, radiological evaluation and surgical outcome was documented.

Results: There was no significant difference between the two studied groups as regard the bony fusion after follow up period and there is no significant difference between the two studied techniques as regard outcome. Favorable outcome was not related to patient gender. But, the favorable outcome was associated with younger age [all patients younger than 40 years had favorable outcome, while $73.7 \%$ of those older than 49 years had been improved.

Conclusion: Titanium mesh cages were found to be similar to autogenous iliac bone graft for restoring vertebral height when treating single-segment lumbar spondylodiscitis and obtained same clinical efficacy as autogenous iliac bone.

Keywords: Spondylodiscitis; Titanium mesh; Comparative; Autogenous; lliac bone graft.

This is an open access article under the Creative Commons license [CC BY] [https://creativecommons.org/licenses/by/2.0/]

Please cite this article as: Selim MSO, El khadrawy SMM, Hassan MMY. Comparative Study between Titanium Mesh and Autogenous lliac Bone Graft through Anterior Approach for Treatment of Lumbar Spondylodiscitis. IJMA 2020; 2[2]: 343350.

* Main subject and any subcategories have been classified according to researchers' main field of study. 


\section{INTRODUCTION}

Spondylodiscitis is an inflammatory process of the vertebral disk space, often related to infection. The commonly affected region is the lumbar one followed by cervical region and finally thoracic spine ${ }^{[1]}$

Spondylodiscitis affected young children and peaks again after the age of 50 yeas [bimodal distribution], with male predominance. The main risk factors are old age, renal impairment, diabetes mellitus, low immunity and intravenous [IV] drug use. In addition, there was an increased risk for development of spondylodiscitis after invasive spinal procedures [the overall rate 0.1 to $4.0 \%, 0.5 \%$ after cervical discectomy, and $0.25 \%$ after lumbar discectomy][2,3].

The etiology of spondylodiscitis is debatable; it could be due to direct hematogenous [spontaneous type] spread [from respiratory or genitourinary infection] or direct spread [post-operative complications] due to introduction of skin flora like staphylococcus aureus. In addition, spinal tuberculosis could be spread along spinal ligaments to adjacent anterior vertebral body. Otherwise, it could be aseptic ${ }^{[4]}$

Patients with spondylodiscitis presented by nonspecific manifestations which could lead to delayed diagnosis up to 2-6 months. Bacterial spondylodiscitis typically presented by back pain not responding to rest or traditional analgesics. On examination, there is local tenderness on palpation and aggravation of symptoms with movement. Neurological deficits are common. Different imaging modalities are available for diagnosis with specific criteria for each modality[5,6],

The main abnormal laboratory findings are increased erythrocyte sedimentation rate and Creactive protein [in about $90.0 \%$ of patients] [1].

Conservative treatment is usually ineffective in majority of patients. Otherwise, percutaneous CTguided drainage of abscesses $>2 \mathrm{~cm}$ could be performed. In addition, surgery is indicated when spinal cord compression or instability are present, when correction of a mechanical deformity is required and drainage of abscess or alleviation of severe pain is indicated. The placement of fixation device in presence of instability did not retard the healing process ${ }^{[2]}$.

The ideal treatment intervention did gain consensus yet. Thus, the present study was designed as a trial to search for the best treatment for lumbar spondylodiscitis.

\section{AIM OF THE WORK}

The aim of the work is to compare between titanium mesh and autogenous iliac bone graft through anterior approach for treatment of lumbar spondylodiscitis.

\section{PATIENTS AND METHODS}

This study was prospective study that was conducted in the Departments of Neurosurgery, AlAzhar faculty of Medicine [Damietta]. A total of [30] patients with lumbar spondylodiscitis who admitted elective surgery were included. After an informed consent was attained from each patient, all were subjected to full history taking [personal, complaint, present, past and family history], clinical assessment [general and neurological examination in a systematic pattern], routine lab investigations and radiological examination [Temporal bone computed tomography for detailed bony anatomy, high resolution computed tomography [CT] scans axial and coronal images. Magnetic resonance imaging brain with and without contrast]. Diagnosis confirmed by computer tomography. Patients receiving conservative treatment were excluded from the study. Surgical intervention was carried out after progressive reduction of erythrocyte sedimentation rate $[E S R]$, and specifically when ESR reduced below $60 \mathrm{~mm} / \mathrm{h}$.

Patients were randomly assigned to one of two equal groups [random numbers were generated using computer software, then each number was assigned to a specific group and preserved in a sealed envelope that opened just before surgical intervention by a nurse not included in the study].

Surgical technique: All operations were carried out while the patient in the supine position with elevated head in comparison to feet. The incision was made in a paramedian plane, midway between umbilicus and symphysis pubis. The affected vertebrae were exposed through an open retroperitoneal approach. A radical debridement was carried out, then an autogenous bone graft [from iliac bone] was inserted in a tight fashion into the L5-S1 
bone groove. Two anterior lumbosacral vertebrae plates [self-locking, made of titanium] [PACH; General Corp., Germany] of appropriate length were anteriorly fixed at L5-S1.

The postoperative care: the drain was removed when volume in the drainage bag $<30 \mathrm{ml} /$ day. Four weeks after surgery, ambulation was permitted. The follow up examination visits were scheduled at 1 and 4 weeks postoperative and in $3,6,12,18$ and 24 months after surgery. Then on annual basis.

\section{Clinical evaluating consisted of:}

1- Clinical evaluation [examination]. The following indices were assessed and recorded in preoperative period, at scheduled follow up visits as described before, starting from the $3^{\text {rd }}$ month. In addition, the duration of surgery, amount of blood loss, length of hospital stays, cost of hospitalizations, pain assessment by visual analogue scale [VAS], change in Oswestry Disability Index [ODI] score, were recorded and statistically analyzed. Furthermore, the neurologic function recovery [evaluated by Frankel grade], Lab investigations with special emphasis on erythrocyte sedimentation rate and Creactive protein were documented.

\section{2- Radiological assessments.}

Many radiological parameters were evaluated [e.g., kyphotic and Cobb's angles, Intervertebral height] were evaluated and recorded. The intervertebral height was recognized as the vertical distance between superior and inferior vertebral body in coronal plane with fusion zone[7]. Bone grafting fusion was assessed according to radiologic manifestations [criteria] described by Bridwell et al. [8]

Ethical Consideration: The study protocol had been submitted for and approved by Institution Research Board [IRB] of faculty of medicine Al-Azhar University. Informed consent had been obtained from each participant sharing in the study. Confidentiality and personal privacy had been respected in all levels of the study.

Data management and Statistical Analysis: Measured variables returned data included in statistical analysis using Statistical package for
Social Science [International Business Machines [IBM] Corp. Released 2011. IBM SPSS Statistics for Windows, Version 20.0. Armonk, NY: IBM Corp.]. Results of numerical parameters expressed as arithmetic mean [average] \pm Standard deviation [SD], while categorical parameters were expressed in frequency and percentages. Student " $f$ " test was used to assess the statistical significance between two means. Chi-Square test or Fisher's exact test examined the relationship between two qualitative variables. $P \leq 0.05$ was considered significant.

\section{RESULTS}

The study included 30 patients, randomly allocated into two equal groups; group 1 treated by titanium mesh, and group 2 treated by autogenous iliac bone graft.

In the present work, both groups 1 and 2 were comparable [i.e., there was no significant difference] as regard patient age, gender, presenting symptoms or past history [detailed results are presented in table 1].

Regarding outcome, there was no significant difference between groups 1 or 2. For example kyphosis, renal impairment, septicamia, incontinence as complications were reported in $66.7 \%, 20.0 \%, 13.3 \%$ and $13.3 \%$ successively in group 1, and in $60.0 \%, 13.3 \%, 13.3 \%$ and $6.7 \%$ successively in group 2. In addition, bony fusion [cm], loss of intervertebral height [cm], operative time [min] and length of hospital stay [days] were 9.3 \pm 3.1 , $1.9 \pm 0.6,240.0 \pm 52.5$ and $8.3 \pm 1.6$ successively in group 1, compared to $8.7 \pm 2.7,2.1 \pm 0.7,240.8 \pm 66.2$ and $7.9 \pm 1.5$ successively in group 2 . Overall, there was improvement among 11 patients in group 1, and 12 patients in group 2. However, the difference was statistically non-significant [Table 2].

In the present work, there was no significant association between patient gender and overall outcome [Table 3]. On the other side, improvement was significantly associated with younger age regardless the surgical procedure [all patients younger than 40 years of age were improved, while $73.7 \%$ of patients older than 40 years of age were improved] [Table 4]. Figures 1 through 3 represented a patients of iliac bone graft group. 
Selim MSO, et al.

Table [1]: Comparison between groups 1 and 2 regarding patient age, gender, clinical presentation and past history

\begin{tabular}{|c|c|c|c|c|}
\hline & & Group 1 & Group 2 & P value \\
\hline \multirow[t]{2}{*}{ Age } & Mean \pm SD & $45.52 \pm 13.48$ & $46.55 \pm 14.11$ & \multirow[t]{2}{*}{$>0.05$} \\
\hline & Range & $21-82$ & $20-78$ & \\
\hline \multirow{2}{*}{$\begin{array}{l}\text { Age group } \\
\text { [years] }\end{array}$} & $\leq 40$ & $6[40.0 \%]$ & $5[33.3 \%]$ & \multirow[t]{2}{*}{$>0.05$} \\
\hline & $>40$ & $9[60.0 \%]$ & $10[66.7 \%]$ & \\
\hline \multirow[t]{2}{*}{ Gender } & Female & $8[53.3 \%]$ & $9[60.0 \%]$ & \multirow[t]{2}{*}{$>0.05$} \\
\hline & Male & $7[46.7 \%]$ & $6[40.0 \%]$ & \\
\hline \multirow{6}{*}{$\begin{array}{l}\text { Clinical } \\
\text { Presentation }\end{array}$} & Radiculopathy & $13[86.7 \%]$ & $14[93.3 \%]$ & $>0.05$ \\
\hline & Claudication pain & $2[13.3 \%]$ & $3[20.0 \%]$ & $>0.05$ \\
\hline & Motor affection & $9[90.0 \%]$ & $8[53.3 \%]$ & $>0.05$ \\
\hline & Sensory affection & $4[26.7 \%]$ & $4[26.7 \%]$ & $>0.05$ \\
\hline & Sphincter affection & $6[40.0 \%]$ & $7[46.7 \%]$ & $>0.05$ \\
\hline & Fever & $3[20.0 \%]$ & $2[13.3 \%]$ & $>0.05$ \\
\hline \multirow{6}{*}{$\begin{array}{l}\text { Past } \\
\text { History }\end{array}$} & Failed spinal surgery & $10[66.7 \%]$ & $9[60.0 \%]$ & $>0.05$ \\
\hline & Diabetes mellitus & $9[60.0 \%]$ & $10[66.7 \%]$ & $>0.05$ \\
\hline & $\mathrm{HCV}$ & $2[13.3 \%]$ & $2[13.3 \%]$ & $>0.05$ \\
\hline & Tuberculosis & $2[13.3 \%]$ & $1[6.7 \%]$ & $>0.05$ \\
\hline & Brucellosis & $1[6.7 \%]$ & $1[6.7 \%]$ & $>0.05$ \\
\hline & Drug addiction & $1[6.7 \%]$ & $2[13.3 \%]$ & $>0.05$ \\
\hline
\end{tabular}

SD: standard deviation; HCV: Hepatitis C virus.

Table [2]: Comparison between studied groups regarding outcome

\begin{tabular}{|c|c|c|c|c|}
\hline & & Group 1 & Group 2 & P value \\
\hline \multirow{4}{*}{ Complications } & Kyphosis & $10[66.7 \%]$ & $9[60.0 \%]$ & 0.704 \\
\hline & Renal impairment & $3[20.0 \%]$ & $2[13.3 \%]$ & 0.801 \\
\hline & Septicemia and death & $2[13.3 \%]$ & $2[13.3 \%]$ & 1.0 \\
\hline & Incontinence & $2[13.3 \%]$ & $1[6.7 \%]$ & 0.98 \\
\hline \multicolumn{2}{|l|}{ Boney fusion [cm] } & $9.3 \pm 3.1$ & $8.7 \pm 2.7$ & 0.576 \\
\hline \multicolumn{2}{|c|}{ Loss of intervertebral height [cm] } & $1.9 \pm 0.6$ & $2.1 \pm 0.7$ & 0.563 \\
\hline \multicolumn{2}{|l|}{ Operative time [min] } & $240.0 \pm 52.5$ & $240.8 \pm 66.2$ & 0.932 \\
\hline \multicolumn{2}{|l|}{ Length of stay [days] } & $8.3 \pm 1.6$ & $7.9 \pm 1.5$ & 0.562 \\
\hline \multirow[t]{2}{*}{ Overall outcome } & Improved & $11[73.3 \%]$ & $12[80.0 \%]$ & \multirow{2}{*}{1.0} \\
\hline & Not improved & $4[26.7 \%]$ & $3[20.0 \%]$ & \\
\hline
\end{tabular}

Table [3]: Association between patient gender and outcome

\begin{tabular}{|c|c|c|c|c|c|c|}
\hline \multirow[t]{2}{*}{ Variable } & \multicolumn{2}{|c|}{$\begin{array}{l}\text { Males } \\
{[n=13]}\end{array}$} & \multicolumn{2}{|c|}{$\begin{array}{c}\text { Females } \\
{[n=17]}\end{array}$} & \multirow[t]{2}{*}{$x^{2}$} & \multirow[t]{2}{*}{$P$ value } \\
\hline & No. & $\%$ & No. & $\%$ & & \\
\hline \multicolumn{7}{|l|}{ Outcome: } \\
\hline $\begin{array}{l}\text { Improved } \\
\text { Not improved }\end{array}$ & $\begin{array}{c}10 \\
3\end{array}$ & $\begin{array}{l}76.9 \\
23.1\end{array}$ & $\begin{array}{c}13 \\
4\end{array}$ & $\begin{array}{l}76.4 \\
23.6\end{array}$ & 0.0 & 1.0 \\
\hline
\end{tabular}

Table [4]: Association between age groups and outcome

\begin{tabular}{|c|c|c|c|c|c|c|}
\hline \multirow[t]{2}{*}{ Variable } & \multicolumn{2}{|c|}{$\begin{array}{c}\leq 40 \\
{[n=11]}\end{array}$} & \multicolumn{2}{|c|}{$\begin{array}{c}>40 \\
{[n=19]}\end{array}$} & \multirow[t]{2}{*}{$x^{2}$} & \multirow[t]{2}{*}{$P$ value } \\
\hline & No. & $\%$ & No. & $\%$ & & \\
\hline \multicolumn{7}{|l|}{ Outcome: } \\
\hline $\begin{array}{l}\text { Improved } \\
\text { Not improved }\end{array}$ & $\begin{array}{c}11 \\
0\end{array}$ & $\begin{array}{c}100.0 \\
0.0\end{array}$ & $\begin{array}{c}12 \\
7\end{array}$ & $\begin{array}{l}73.7 \\
26.7\end{array}$ & Fisher test & $\begin{array}{l}0.02 \\
{[S]}\end{array}$ \\
\hline
\end{tabular}




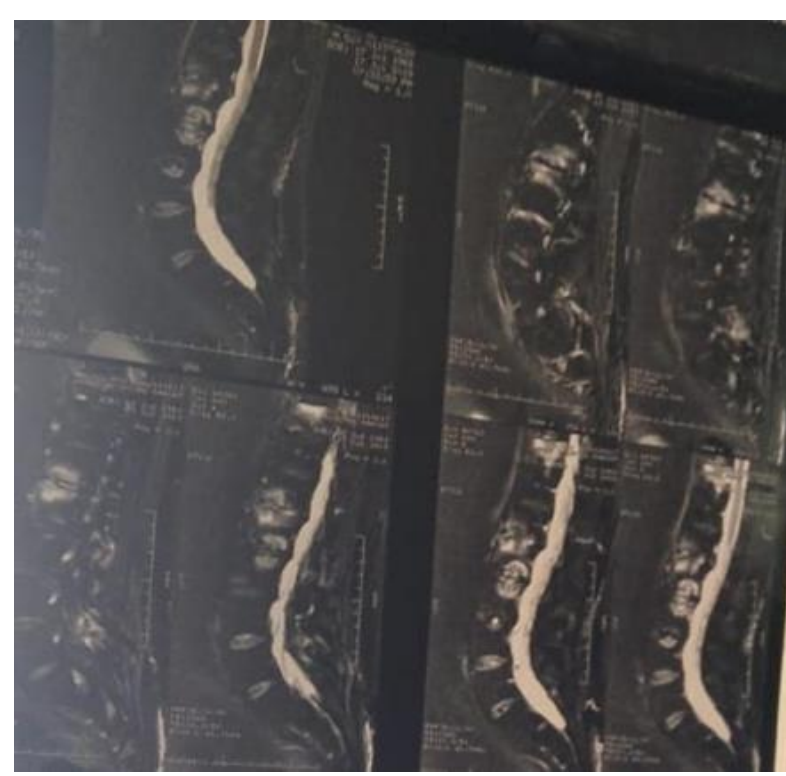

a

Figure [1a,b]: preoperative MRI lumbosacral spine revealed lumbar [L2-L3] spondylodiscitis

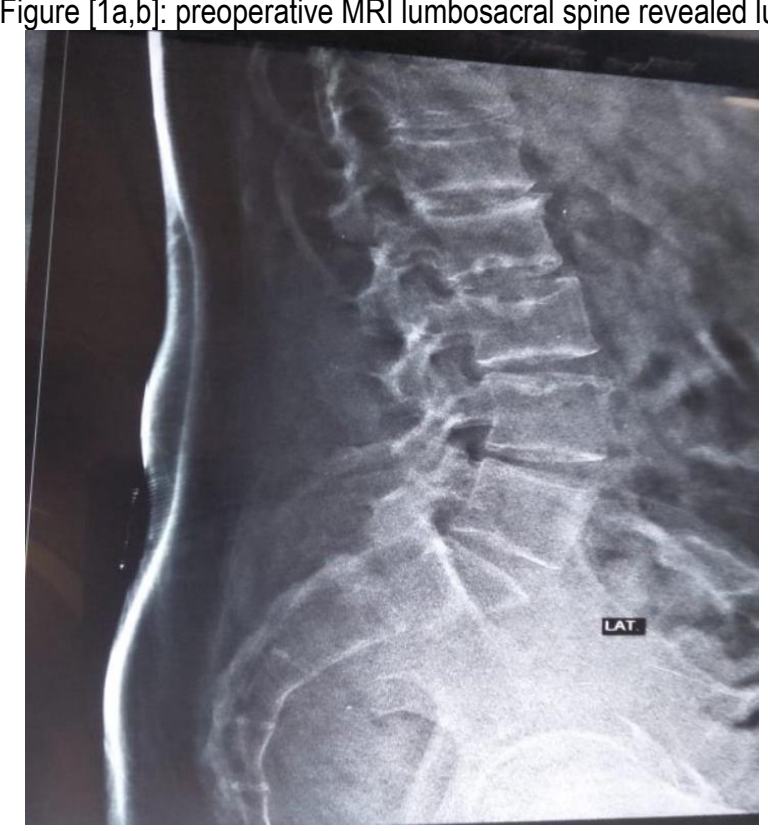

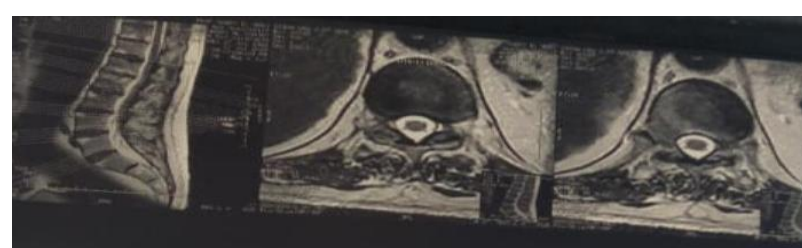
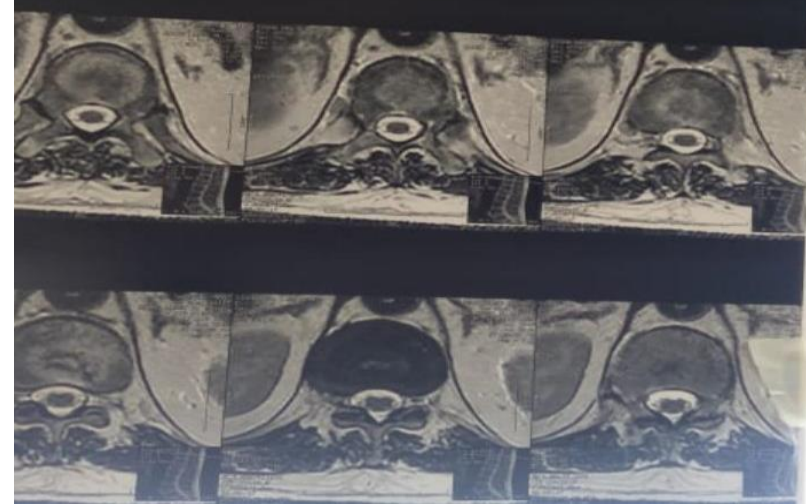

b

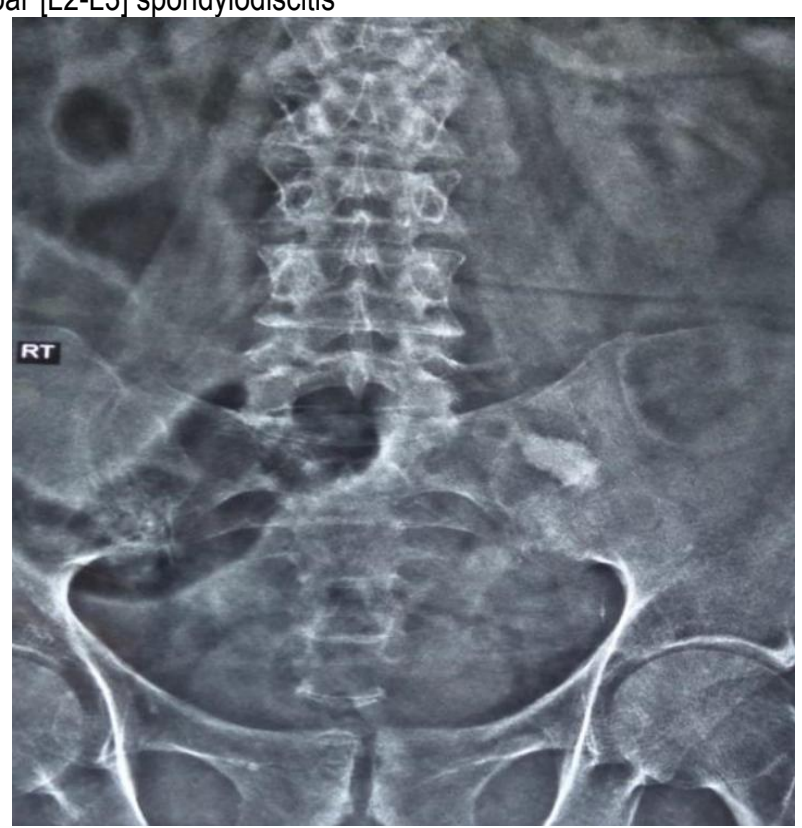

Figure [2]: Preoperative X-ray of the same patien revealed lumbar spondylodiscitis [a: lateral veiw; p: PA view].

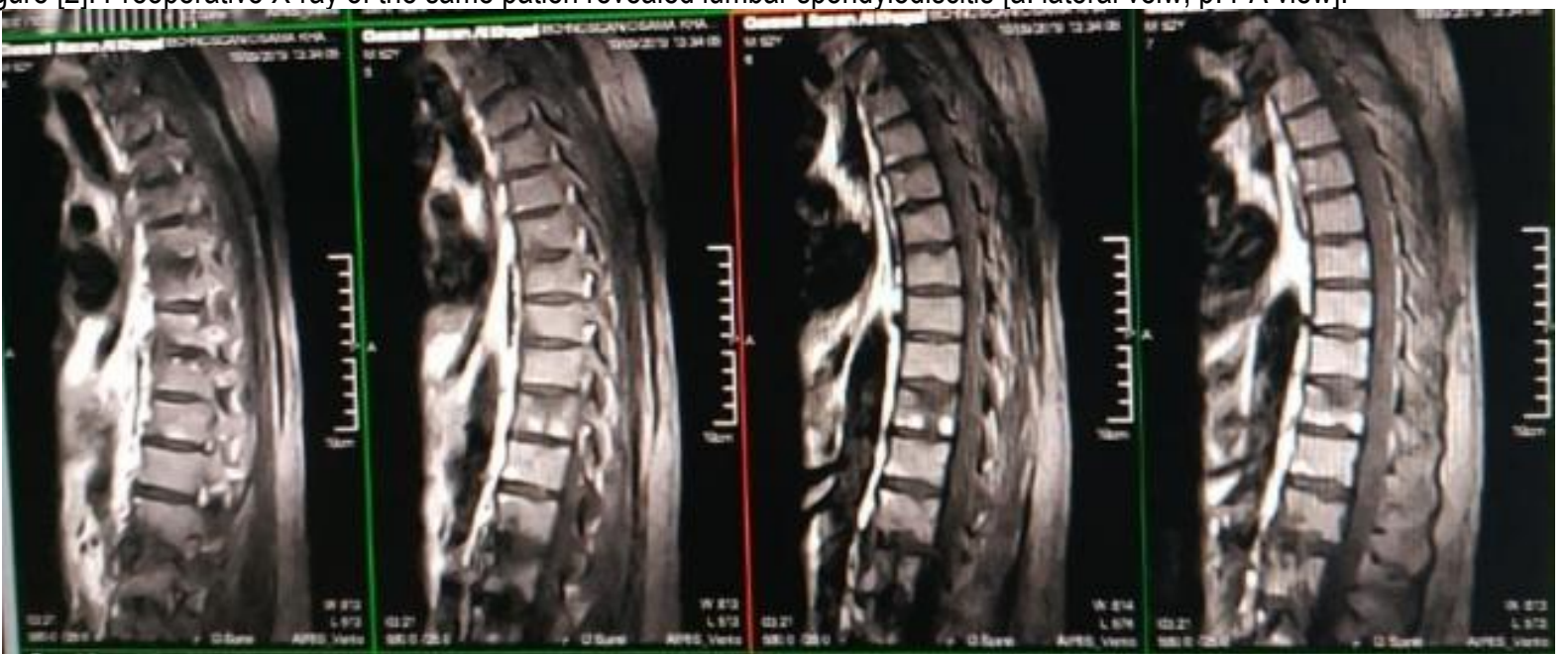

Figure [3]: Postoperative MRI, lumbosacral spine revealed lumbar fusion after bone graft [anterior approach] 


\section{DISCUSSION}

In the present work, the mean age was $45.52 \pm 13.48$ and $46.55 \pm 14.11$ in groups 1 and 2 respectively, with no significant difference between groups. This is older than age reported in the study of $\mathrm{He}$ and $\mathrm{Xu}^{[0]}$, who reported a mean age of 36 years and 40 years of groups 1 and 2 respectively. This could be attributed to different inclusion criteria. On the other side, Gao et al.[10] reported nonsignificant difference between groups regarding demographic data, as in the present work.

In agreement with the present work, Sundararaj et al.[11] reported that, the lumbar spine was the predominant level of involvement in spondylodiscitis, and medical comorbidities were seen in $25.7 \%$ patients, with multiple comorbidities reported among 7.1\%. In addition, Ozalay et al.[12], found that medical comorbidities were present in all patients in their participants except two,, and the most common was diabetes mellitus. All patients had fever and pain on palpation.

Regarding bony fusion, the present study revealed that, there is no significant difference between groups 1 and $2[9.3 \pm 3.1$ vs $8.7 \pm 2.7$ respectively]. In addition, there is no significant difference regarding Loss of intervertebral height [ $1.9 \pm 0.6$ vs $2.1 \pm 0.7$ in groups 1 and 2 respectively]. In agreement with our study, Gao et al.[10] revealed that, at the endpoint of their study, complete cure with solid bone fusion was achieved for all patients. The correction of Cobb's angle and rebuilding of intervertebral height markedly improved compared with pre-operation, but not reach significant difference among three surgical techniques. But, in another study of Sundararaj et al.[11] the bony fusion was seen in $93.7 \%$ of patients with titanium cases, $6.3 \%$ had pseudoarthrosis, one patient had subsiding of the cage and a 22 degree loss of correction by the $34^{\text {th }}$ month with a proximal screw backing out and subcutaneous eminence. The radiological nonunion was asymptomatic in remaining patients and no further surgical intervention required for any of them.

Surgical treatment has become an important way of the management of severe spinal tuberculosis. The anterior-posterior approach is considered the gold standard for surgical treatment, but limited by its complications as blood loss. Posterior approach was reported to accomplish good clinical outcome when used to treat spinal tuberculosis[12]. Vertebral height needs reconstruction after surgical debridement, but it is still elusive to select suitable bone-grafting materials to reconstruct the vertebral height. Clinically, titanium mesh and autogenous bone [iliac] graft are ubiquitous ${ }^{[11]}$. On the other side, Yin et al.[13] reported that, the anterior approach for exposure of the upper thoracic vertebrae had some difficulty caused by thoracic bones [working as a barrier], costal bone, superior mediastinum organs and the clavicle. In addition, it had long operative time, profuse bleeding, large wound and needs prolonged rest in bed.

Results of the present work revealed comparable results between both groups regarding operative time and length of stay. Similarly, Gao et al.[10], reported no statistically significant difference was found when analyzing duration of hospital stay.

The most critical dispute against usage of titanium cages in management of spondylodiscitis comes from the wrong belief that all foreign substances had a tendency to work as a ready-made medium for bacterial adherence and biofilm creation thus reducing antibiotic penetration [14].

According to outcomes, the present study found that there is no significant difference between the two studied techniques as regard outcome, there is no significant relation between gender and outcome while there is significant relation between age and outcome. The outcomes of the clinical study of Sundararaj et al.[11] showed a high healing rate, adequate rebuilding and preservation of sagittal alignment, early mobilization due to absences of pain, a lower rate of comorbidities and no late recurrences of infection, and Christodoulou et al.[15], who advocates that, use of cages confers precise, more secure, and reliable correction of deformity than when structural bone graft was used. Talu et al.[16], reported complications such as slippage of bone graft in 3 and resorption in 2 of 127 patients. These comorbidities are easily treated when titanium cages were used, as they have teeth that 'bite' into the adjacent vertebrae when compressed, helping a secure attachment within bone. This has the advantages of being obtainable in the direct post-operative period, allowing early patient ambulation, with no stress on the diseased segments. 
In Gao et al.[10], both groups of single-segment titanium mesh and autogenous iliac bone reached solid bone fusion with recovery or improvement of neurological function in all patients, except one patient who had grade $D$ and another one who had loss of intervertebral height. However, titanium cages permit had the advantages of reshaping according to individual defects. In addition, titanium mesh could be filled with small fragments of cancellous bone [excised from vertebral lamina and articular processes] which avoids complications of donor's site, and spinal instability was improved by insertion to the resection site, with provision of large interbody bone interface[10].

The treatment of multiple-level spinal tuberculosis requires bone graft with strong mechanical stability force. In such circumstances, the autogenous iliac bone graft had many disadvantages being liable to stress fractures, failure of fixation and inability to correct kyphosis ${ }^{[17]}$. In addition to donor site comorbidities such as pain [40.0\%] and infection[18]. Zeng et al.[12] and Korovessis et al.[19] reported that a long-segment bone graft was more liable to stress fractures, poor correction of kyphosis and implant failure.

In earlier trials Qureshi et al.[17]; Erturer et al.[20], and in contrast to our work, titanium mesh provided better structural support, solid fusion, correction of kyphosis and restoration of intervertebral height, and smaller loss of angular correction and intervertebral height than autogenous bone graft when treating multi-segment spinal TB. Also, Bone fragments harvested from intraoperative biting were adequate to fill the titanium mesh for induction of bone fusion.

However, recommendations for optimal surgical treatment are still debatable. The principle aims of surgery comprise quick decompression and adequate stabilization, forceful debridement and tissue sample harvesting[21].

There is a wide range of surgical preferences, containing anterior, posterior or combined procedures and single-stage or two-stage techniques, with or without instrumentation. Less invasive endoscopic maneuvers for debridement and restoration have also been defined. However, open surgery still the gold standard of care, mainly in cases of extensive bone destruction[22].

Due to absence of specific rules for the optimal procedure, surgeons often come to a decision taking into account the general health, the most suitable spinal maneuver and instrumentation tailored to the characteristics of each patient and the individual surgeon's preference[23].

In conclusion, titanium mesh cages were found to be similar to autogenous bone [iliac] graft for reconstruction of vertebral height when dealing with single-segment lumbar spondylodiscitis and presented the same clinical efficacy as autogenous iliac bone graft. Further, larger number of patients and longer follow-ups would be required.

Financial and Non-financial Relationships and Activities of Interest

None to disclose

\section{REFERENCES}

1. Cottle L, Riordan T. Infectious spondylodiscitis. J Infect. 2008; 56 [6]:401-12. [DOI: 10.1016/j.jinf.2008.02.005].

2. Gerometta A, Bittan F, Rodriguez Olaverri JC. Postoperative spondilodiscitis.Int Orthop. 2012 Feb;36 [2]: 433-8. [DOI: 10.1007/s00264-011-1442-0].

3. Principi N, Esposito S. Infectious Discitis and Spondylodiscitis in Children. Int J Mol Sci. 2016 Apr 9;17[4]:539. [DOI:10.3390/ijms17040539].

4. Langlois S, Cedoz JP, Lohse A, Toussirot E, Wendling D. Aseptic discitis in patients with ankylosing spondylitis: a retrospective study of 14 cases. Joint Bone Spine. 2005 May; 72[3]:248-53. [DOI:10.1016/j.jbspin. 2004.05.015]

5. Herren C, Jung N, Pishnamaz M, Breuninger M, Siewe J, Sobottke R. Spondylodiscitis: Diagnosis and treatment options. Dtsch Arztebl Int. 2017 Dec 25;114[5152]:875-882. [DOI: 10.3238/arztebl.2017.0875].

6. Raghavan M, Lazzeri E, Palestro CJ. Imaging of Spondylodiscitis. Semin Nucl Med. 2018; 48[2]:131147. [DOI: 10.1053/j.semnuclmed.2017. 11.001].

7. Zaveri GR, Mehta SS. Surgical treatment of lumbar tuberculous spondylodiscitis by transforaminal lumbar interbody fusion [TLIF] and posterior instrumentation. J Spinal Disord Tech. 2009; 22:257-262. [DOI: 10.1097/ BSD. 0b 013e 31818859d0].

8. Bridwell KH, Anderson PA, Boden SD, Vaccaro AR, Wang JC. What's new in spine surgery? J Bone Joint Surg Am. 2005; 87[8]: 1892-901. [DOI: 10.2106/ JBJS.E. 00444].

9. He Q, Xu J. Comparison between the antero-posterior and anterior approaches for treating L5-S1 vertebral tuberculosis. Int Orthop. 2012; 36[2]: 345-351. [DOI: 10.1007/s00264-011-1307-6].

10. Gao Y, Ou Y, Deng Q, He B, Du X, Li J. Comparison between titanium mesh and autogenous iliac bone graft 
to restore vertebral height through posterior approach for the treatment of thoracic and lumbar spinal tuberculosis. PloS one 2017; 12[4], e0175567. [DOI: $10.1371 /$ journal.pone.0175567].

11. Sundararaj GD, Amritanand R, Venkatesh K, Arockiaraj $J$. The Use of Titanium Mesh Cages in the Reconstruction of Anterior Column Defects in Active Spinal Infections: Can We Rest the Crest? Asian Spine J. 2011; 5[3]:155-61.. [DOI: 10.4184/asj.2011.5.3.155].

12. Ozalay M, Sahin O, Derincek A, Onay U, Turunc T, Uysal M. Non-tuberculous thoracic and lumbar spondylodiscitis: single-stage anterior debridement and reconstruction, combined with posterior instrumentation and grafting; Acta Orthopædica Belgica. 2010; 76 [1]: 100-106. [PMID:20306973].

12. Zeng H, Zhang P, Shen X, Luo C, Xu Z, Zhang Y, Zhang $Y$, Liu Z, Wang $X$. One-stage posterior-only approach in surgical treatment of single-segment thoracic spinal tuberculosis with neurological deficits in adults: a retrospective study of 34 cases. BMC Musculoskelet Disord. 2015; 16: 186. [DOI: 10.1186/s12891-0150640-0].

13. Yin $X H$, Zhou ZH, Yu HG, Hu XK, Guo Q, Zhang $\mathrm{HQ}$. Comparison between the antero-posterior and posterior only approaches for treating thoracolumbar tuberculosis [T10-L2] with kyphosis in children: a minimum 3-year follow-up. Child's nervous system: Childs Nerv Syst. 2016 Jan;32[1]:127-33. [DOI: 10.1007/s00381-015-2935-8].

14. Ha KY, Chung YG, Ryoo SJ. Adherence and biofilm formation of Staphylococcus epidermidis and Mycobacterium tuberculosis on various spinal implants. Spine [Phila Pa 1976] 2005; 30:38-43. [DOI:10.1097/ 01.brs.0000147801.63304.8a].

15. Christodoulou AG, Givissis P, Karataglis D, Symeonidis PD, Pournaras J. Treatment of tuberculous spondylitis with anterior stabilization and titanium cage. Clin Orthop Relat Res 2006; 444:60-5. 7. [DOI: 10.1097/01.blo.0000201175.87635.28].

16. Talu U, Gogus A, Ozturk C, Hamzaoglu A, Domanic U. The role of posterior instrumentation and fusion after anterior radical debridement and fusion in the surgical treatment of spinal tuberculosis: experience of 127 cases. J Spinal Disord Tech 2006; 19:554-9 [DOI: 10.1097/01.bsd.0000211202. 93125.c7].
17. Qureshi MA, Khalique AB, Afzal W, Pasha IF, Aebi M. Surgical management of contiguous multilevel thoracolumbar tuberculous spondylitis. Eur Spine J. 2013; 22 Suppl 4:618-23. [DOI:10.1007/s00586-0122459-9].

18. Wang B, L G, Liu W, Cheng I. Anterior radical debridement and reconstruction using titanium mesh cage for the surgical treatment of thoracic and thoracolumbar spinal tuberculosis: minimum five-year follow-up. Turk Neurosurg. 2011; 21[4]:575-81. [DOI: 10.5137/10195149.Jtn.4639-11.1].

19. Korovessis P, Petsinis G, Koureas G, lliopoulos P, Zacharatos S. Anterior surgery with insertion of titanium mesh cage and posterior instrumented fusion performed sequentially on the same day under one anesthesia for septic spondylitis of thoracolumbar spine: is the use of titanium mesh cages safe? Spine 2006; 31[9]:1014-9. [DOI:10.1097/ 01.brs.0000215049.08622.9d].

20. Erturer E, Tezer M, Aydogan M, Mirzanli C, Ozturk I. The results of simultaneous posterior-anterior-posterior surgery in multilevel tuberculosis spondylitis associated with severe kyphosis. Eur Spine J. 2010; 19[12]:2209 15. [DOI: 10.1007/s00586-010-1481-z].

21. Duarte RM, Vaccaro AR. Spinal infection: state of the art and management algorithm. Eur Spine J.2013; 22:2787-2799. [DOI: 10.1007/s00586-013-2850-1].

22. Ito M, Abumi K, Kotani Y, Kadoya K, Minami A. Clinical outcome of posterolateral endoscopic surgery for pyogenic spondylodiscitis: results of 15 patients with serious comorbid conditions. Spine [Phila $\mathrm{Pa}$ 1976] 2007; 32:200-206. [DOI: 10.1097/01.brs. 0000251645.58076.96].

23. Mavrogenis AF, Igoumenou $\mathrm{V}$, Tsiavos $\mathrm{K}$, Megaloikonomos P, Panagopoulos GN, Vottis C, et al. When and how to operate on spondylodiscitis: a report of 13 patients. Eur $J$ Orthop Surg Traumatol. 2016; 26:31-40. [DOI:10.1007/s00590-0151674-6]. 